\section{Wildlife collisions put a dent in road safety}

In September 2020, the United Nations (UN) adopted a resolution to halve road traffic deaths and injuries by 2030 (1). A Global Plan for the Decade of Action for Road Safety (2) was developed that emphasized the importance of a holistic approach to road safety, including the improvement of the design of roads and vehicles and the enhancement of laws. However, the Global Plan overlooks wildlife-vehicle collisions.

Millions of wildlife-vehicle collisions occur every day around the world (3-5), causing countless human deaths and injuries, and high vehicle damage costs (6). Virtually all species that live in the vicinity of roads are threatened by wildlifevehicle collisions, causing significant negative effects on biodiversity (3-5). Hence, reducing wildlife-vehicle collisions goes hand in hand with improving road safety, while also promoting biodiversity conservation.

In line with the UN resolution, we suggest promoting simple but effective mitigation actions. Installation of proper fencing linked to existing road-crossing structures (such as culverts for water drainage) can prevent wildlife crossings on the road (7). Given that most wildlife-vehicle collisions occur at night, nocturnal traffic should be substantially decreased or slowed, where possible. Such measures should be integrated in road construction and mitigation legislation. More ambitiously, the car industry should target the integration of Artificial Intelligence technology, which could help to prevent collisions by automatically detecting animals approaching the road and warning the driver in real time (8). Adopting plans and policies to reduce wildlife-vehicle collisions will be a step toward meeting the UN goal of a sustainable transport system.

Fernando Ascensão ${ }^{1 *}$, Rafael Barrientos ${ }^{2}$, Marcello D'Amico ${ }^{3}$

${ }^{1}$ Centre for Ecology, Evolution and Environmental Changes, Faculdade de Ciências, Universidade de Lisboa, Lisboa, Portugal. ${ }^{2}$ Road Ecology Lab, Department of Biodiversity, Ecology and Evolution, Faculty of Biology, Complutense University of Madrid, E-28040, Madrid, Spain. ${ }^{3}$ Department of Conservation Biology, Estación Biológica de Doñana, Consejo Superior de Investigaciones Científicas, Sevilla, Spain. *Corresponding author. Email: fjascensao@fc.ul.pt

REFERENCES AND NOTES

1.UN General Assembly, "Improving global road safety" (2020); https://undocs.org/en/A/RES/74/299.

2.WHO, Global Plan for the Decade of Action for Road Safety 2021-2030 (2021); https://www.who.int/publications/m/item/globalplan-for-the-decade-of-action-for-road-safety2021-2030.

3.R. Forman et al., Road ecology: science and solutions (Island Press, 2003).

4. C. Grilo, E. Koroleva, R. Andrášik, M. Bíl, M. GonzálezSuárez, Front. Ecol. Environ. 18, 323 (2020).

5. R. Barrientos, F. Ascensão, M. D’Amico, C. Grilo, H. M. Pereira, Perspect. Ecol. Conserv. 19, 411 (2021).

6. M. R. Conover, Human-Wildlife Interact. 13, 12 (2019).
7. D. Lesbarrères, L. Fahrig, Trends Ecol. Evol. 27, 374 (2012).

8. F. Ascensão, C. Branquinho, E. Revilla, Nat. Electron. 3, 295 (2020).

10.1126/science.abm8468

This is the peer reviewed version of the following article: Ascensão, F., Barrientos, R., \& D'Amico, M. (2021). Wildlife collisions put a dent in road safety. Science, 374(6572), 1208-1208., which has been published in final form at https://www.science.org/doi/10.1126/science.abm8468 